\begin{tabular}{|c|l|}
\hline Title & $\begin{array}{l}\text { Synthesis of quinazoline 2,4(1H,3H)-dione from carbon dioxide and 2-aminobenzonitrile using mesoporous smectites } \\
\text { incorporating alkali hydroxide }\end{array}$ \\
\hline Author(s) & Fujita, Shin-ichiro; Tanaka, Masahiro; A rai, Masahiko \\
\hline Citation & $\begin{array}{l}\text { Catalysis Science \& Technology, 4(6), 1563-1569 } \\
\text { https://doi.org/10.1039/c3cy00977g }\end{array}$ \\
\hline Issue Date & 201406-01 \\
\hline Doc URL & http://hdl.handle.net/2115/57663 \\
\hline Type & article (author version) \\
\hline File Information & Revised manuscript 300.pdf \\
\hline
\end{tabular}

Instructions for use 


\title{
Synthesis of quinazoline-2,4(1H,3H)-dione from carbon dioxide and 2-aminobenzonitrile using mesoporous smectites incorporated with alkali hydroxide
}

\author{
Shin-ichiro Fujita, Masahiro Tanaka and Masahiko Arai* \\ Division of Chemical Process Engineering, Faculty of Engineering, Hokkaido University, \\ Sapporo 060-8628, Japan
}

\begin{abstract}
A series of magnesium containing mesoporous smectites has been prepared with and without incorporation of alkali hydroxide $(\mathrm{NaOH}, \mathrm{KOH}$ or $\mathrm{LiOH})$ and employed for the reaction of $\mathrm{CO}_{2}$ with aminobenzonitrile to produce quinazoline-2,4(1H,3H)-dione. The effects of the quantity and kind of the incorporated alkali atoms on the catalytic properties of the smectites were investigated. Characterization of the smectites has shown that the incorporation of alkali atoms reduces their surface area and total pore volume but enhances the amount and strength of their basic sites. The product yield is increased with the content of alkali atoms incorporated. The incorporation of $\mathrm{Li}$ was less effective than $\mathrm{Na}$ and $\mathrm{K}$ for the enhancement of the yield. It has been suggested that weak and/or moderate base sites are responsible for the reaction. The active sites should be alkali hydroxide particles exsiting between the smectite layers for the alkali incorporated smectites, while $\mathrm{Mg}$ atoms and/or the neighboring $\mathrm{O}$ atoms for the un-incorporated smectite. The $\mathrm{Na}$ incorporated smectite was deactivated by repeated catalyst recycling, while such deactivation was not observed with the un-incorporated smectite. The reason for the deactivation was discussed in connection with the structures of the active sites and the actions of reaction intermediate.
\end{abstract}

\section{Introduction}

$\mathrm{CO}_{2}$ is a cheap, abundant natural carbon source and one of the important $\mathrm{C}_{1}$ building blocks, and it can sometimes replace toxic chemicals such as phosgene, isocyanates or carbon monoxide, leading to greener processes. ${ }^{1-3}$ However, because of its inert nature, developing efficient catalytic processes for the utilization of $\mathrm{CO}_{2}$ for organic synthesis still remains as a challenging task. Recently, efforts were made for the reaction of $\mathrm{CO}_{2}$ with aminobenzonitriles 1 to produce rather complex molecules of quinazoline-2,4(1H,3H)-diones 2 (Scheme 1), 
which are a class of important intermediates in the pharmaceutical industry as a key building block for the synthesis of several useful and valuable medicines. For this reaction, $\mathrm{CO}_{2}$ can replace toxic reagents of phosgene, potassium cyanate, and chrolosufonyl isocyanate, which have been employed for the conventional synthesis of $2 .^{4-8}$ Several research groups reported various catalyst systems for the synthesis of $\mathbf{2}$ by reacting $\mathrm{CO}_{2}$ with $\mathbf{1}$. Those include organic bases of 1,8-diazabicyclo[5.4.0]undec-7-ene (DBU), ${ }^{9-12} \quad N$-methyl-tetrahydropyrimidine (MTHP), ${ }^{13}$ polymer-supported amidine (poly-amidine), ${ }^{13}$ and tetramethylguanidine (TMG) ${ }^{14}$ an inorganic base of $\mathrm{Cs}_{2} \mathrm{CO}_{3}{ }^{15}$ ionic liquids of 1-butyl-3-methylimidazolium hydroxide $([\mathrm{Bmim}] \mathrm{OH})^{16}$ and 1-butyl-3-methylimidazolium acetate ([Bmim] Ac) ${ }^{17}$ a solid base catalyst of $\mathrm{MgO} / \mathrm{ZrO}_{2},{ }^{18}$ and a monomeric tungstate of $\left.\left[\left(n-\mathrm{C}_{4} \mathrm{H}_{9}\right)_{4} \mathrm{~N}^{+}\right)\right]_{2}\left[\mathrm{WO}_{4}\right]\left(\mathrm{TBA}_{2}\left[\mathrm{WO}_{4}\right]\right) .{ }^{19}$ Recently, Han et al. have reported that the reaction of $\mathrm{CO}_{2}$ and $\mathbf{1}$ can proceed in water without any catalyst. ${ }^{20}$ Although this reaction system is interesting, it requires higher reaction temperatures and longer reaction time to get $\mathbf{2}$ with reasonable yields.

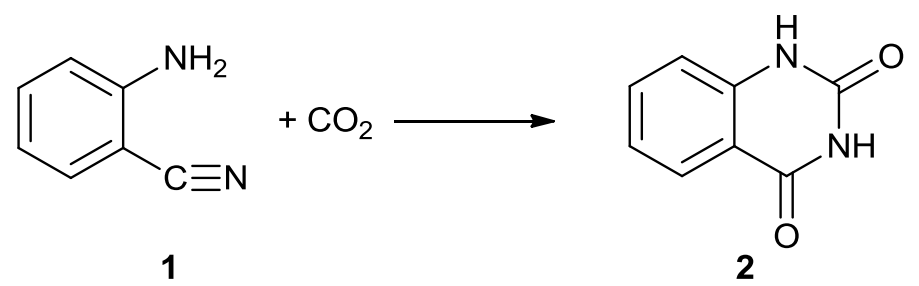

Scheme 1 Synthesis of quinazoline-2,4(1H,3H)-dione 2 from $\mathrm{CO}_{2}$ and aminobenzonitrile 1.

Synthesized smectites are a new kind of mesoporous materials. ${ }^{21-23}$ Smectite is one of the layered clay minerals in which one layer consists of one octahedral sheet sandwiched by two tetrahedral sheets. The octahedral sheet contains divalent or trivalent cations such as $\mathrm{Mg}^{2+}, \mathrm{Zn}^{2+}, \mathrm{Fe}^{3+}$ and $\mathrm{Al}^{3+}$ surrounded by six oxygen atoms and the tetrahedral sheet contains $\mathrm{Si}^{4+}$ cations surrounded by four oxygen atoms. Those divalent or trivalent metal cations make the acidic and basic properties of the smectites tunable. ${ }^{21-29}$ The tri-layers are negatively charged and are held together by electrostatic interaction with exchangeable cations in the interlayer region. Additionally, incorporation of alkali atoms into smectites is also possible. ${ }^{27,30}$ As the first step of the synthesis of smectites, precursor materials are prepared by mixing aqueous solutions of raw materials (water glass and divalent or trivalent metal salt). Then, the slurries of the precursors and water are treated hydrothermally. By adding alkali compounds into the slurry before the hydrothermal treatment, alkali atoms can be introduced into smectites. Our group has reported that the incorporation of alkali atoms into the smectites makes them good catalysts for such base catalyzed reactions as transesterification of ethyl 
acetate with methanol, Knoevenagel condensation of benzaldehyde with ethyl cyanoacetate, and some other reactions relevant to chemical fixation of $\mathrm{CO}_{2}$ to organic carbonate compounds. ${ }^{31-34}$ These observations led us to the use of alkali incorporated basic smectites for the synthesis of 2 .

In the present study, a series of magnesium containing smectites into which various amounts of alkali hydroxide were incorporated were prepared and used for this reaction. The effects of the quantity and kind of the incorporated alkali atoms on the catalytic properties of the smectites were investigated. The reaction results were discussed in connection with the basic properties of the catalysts that were determined by temperature programmed desorption of adsorbed $\mathrm{CO}_{2}$.

\section{Results}

\section{Influence of catalyst composition on textural properties and catalytic activity}

Table 1 lists the chemical compositions determined by an X-ray fluorescence method (XRF), BET surface areas, total pore volumes, and average pore diameter of the smectite catalysts prepared. Both the BET surface area and the total pore volume tended to decrease with the increasing amount of alkali atoms incorporated and the average pore diameter did not change with the content of alkali atoms, except for SM-Li that had a slightly larger average pore diameter. As already discussed, ${ }^{34}$ the decreases of the BET surface area and the total pore volume can be explained by the presence of alkali hydroxide particles between the layers of smectite structure on the basis of a model of "smectite-intercalated smectite" proposed by Torii et al. ${ }^{17,18}$

The reaction of 1 and $\mathrm{CO}_{2}$ were carried out using those smectite catalysts prepared. Fig. 1 plots the yield of product 2 against the amount of alkali atoms incorporated. The lowest yield was obtained with SM and it was increased with increasing the amount of $\mathrm{Na}$ incorporated. Similar enhancement in the yield was also observed with SM-K and SM-Li; however, Li incorporation was less effective for the enhancement in the yield compared to $\mathrm{Na}$. This may partly be explained by the formation of lithium silicate, ${ }^{34}$ which is considered to be catalytically inactive. Such alkali silicate compounds were not observed to form for all SM-Na and SM-K samples. As shown in Table 1, the BET surface area and the total pore volume tended to decrease with the increasing amount of alkali atoms incorporated. Those 
textural properties cannot explain the differences in the catalytic activity among the smectites used. The basic properties of them should be responsible for those differences.

Table 1 Composition and textural properties of smectite catalysts prepared. ${ }^{\text {a }}$

\begin{tabular}{|c|c|c|c|c|c|c|c|c|c|}
\hline \multicolumn{2}{|c|}{ Catalyst } & \multicolumn{5}{|c|}{ Number of atoms per unit cell } & \multirow{2}{*}{$\begin{array}{c}\mathrm{S}_{\mathrm{BET}} \\
\left(\mathrm{m}^{2} / \mathrm{g}\right)\end{array}$} & \multirow{2}{*}{$\begin{array}{c}\mathrm{V}_{\text {pore }} \\
\left(\mathrm{cm}^{3} / \mathrm{g}\right)\end{array}$} & \multirow{2}{*}{$\begin{array}{l}\mathrm{d}_{\mathrm{av}} \\
(\mathrm{nm})\end{array}$} \\
\hline & & $\mathrm{Si}$ & $\mathrm{Mg}$ & $\mathrm{Na}$ & $\mathrm{K}$ & $\mathrm{Li}$ & & & \\
\hline $\mathrm{a}$ & SM & 8.0 & 4.60 & 0.06 & 0 & 0 & 463 & 0.433 & 2.53 \\
\hline $\mathrm{b}$ & SM-Na-1 & 8.0 & 5.67 & 0.84 & 0 & 0 & 695 & 0.440 & 2.46 \\
\hline $\mathrm{c}$ & SM-Na-2 & 8.0 & 5.88 & 1.51 & 0 & 0 & 392 & 0.242 & 2.46 \\
\hline $\mathrm{d}$ & SM-Na-3 & 8.0 & 5.89 & 1.80 & 0 & 0 & 379 & 0.233 & 2.47 \\
\hline $\mathrm{e}$ & SM-Na-4 & 8.0 & 6.09 & 2.25 & 0 & 0 & 173 & 0.107 & 2.48 \\
\hline $\mathrm{f}$ & SM-Na-5 & 8.0 & 6.13 & 2.45 & 0 & 0 & 200 & 0.124 & 2.52 \\
\hline $\mathrm{g}$ & SM-K & 8.0 & 6.09 & 0.47 & 1.7 & 0 & 190 & 0.126 & 2.65 \\
\hline h & SM-Li & 8.0 & 5.41 & 0.47 & 0 & 2.56 & 118 & 0.124 & 4.22 \\
\hline
\end{tabular}

${ }^{\mathrm{a}} \mathrm{S}_{\mathrm{BET}}, \mathrm{V}_{\text {pore }}$ and $\mathrm{d}_{\mathrm{av}}$ denote BET surface area, total pore volume, and average pore diameter, respectively.

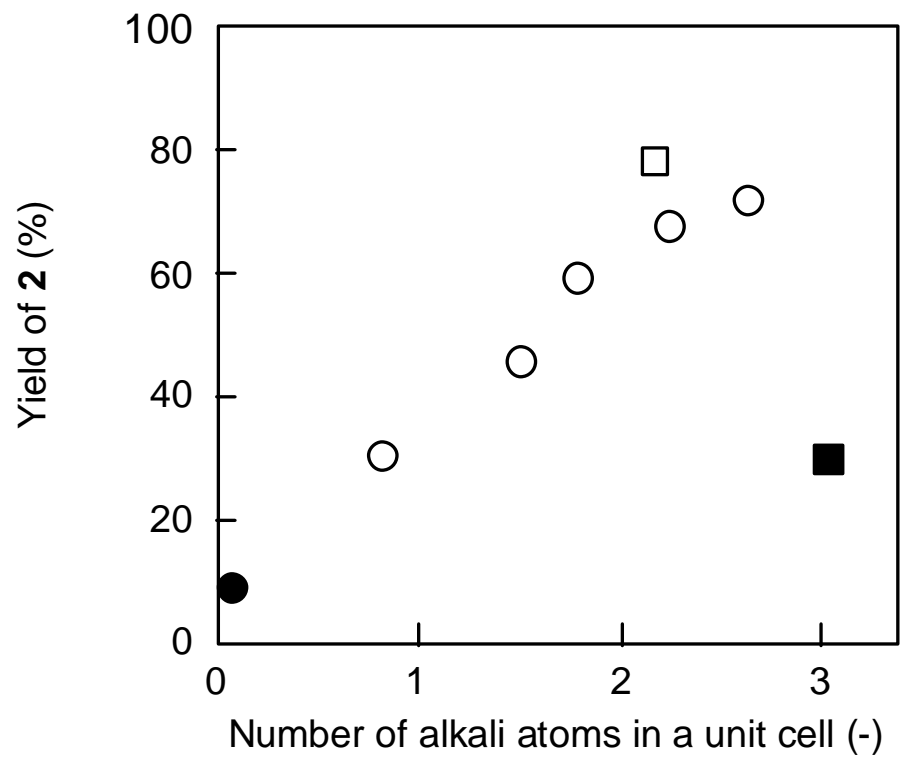

Fig. 1 Influence of the amount of alkali atoms incorporated on the activity of smectite catalysts for the synthesis of 2 from $\mathrm{CO}_{2}$ and 1. ( $~$ ), SM; ( $\bigcirc$ ), SM-Na; ( $\square$ ), SM-K; ( ), SM-Li. Reaction conditions: catalyst, $0.4 \mathrm{~g} ; \mathbf{1}, 8.5 \mathrm{mmol} ; \mathrm{CO}_{2}, 4 \mathrm{MPa}$ (at r. t.); DMF, $10 \mathrm{~cm}^{3} ; 130{ }^{\circ} \mathrm{C}$; time, $6 \mathrm{~h}$. 
The basic properties of smectite catalysts synthesized were examined by TPD of adsorbed $\mathrm{CO}_{2}$. Fig. 2 shows the TPD profiles obtained. SM showed small $\mathrm{CO}_{2}$ desorption peaks around $90{ }^{\circ} \mathrm{C}$ and $180{ }^{\circ} \mathrm{C}$ and all the SM-Na catalysts showed the ones around $100{ }^{\circ} \mathrm{C}$ and $250{ }^{\circ} \mathrm{C}$. With increasing $\mathrm{Na}$ content, the intensity of the peak at $250{ }^{\circ} \mathrm{C}$ increased and tended to level off at larger Na contents. In addition to these two peaks, three peaks appear above $600{ }^{\circ} \mathrm{C}$ over SM-Na samples containing large amounts of $\mathrm{Na}$ and they grow with its content. $\mathrm{CO}_{2}$ TPD profiles obtained with SM-K and SM-Li were slightly different from those over SM-Na. SM-K and SM-Li showed only one broad peak above $600^{\circ} \mathrm{C}$ and the latter catalyst also showed a peak at $480{ }^{\circ} \mathrm{C},{ }^{34}$ which is not observed over the other catalysts. Thus, the peak intensity and temperature are different among the catalysts, meaning that the strength and the number of base sites vary with the composition of the catalysts. The peak around $100{ }^{\circ} \mathrm{C}$ was ascribable to both the desorption of $\mathrm{CO}_{2}$ physisorbed and of $\mathrm{CO}_{2}$ adsorbed on weak base sites; however, the contribution of physisorbed $\mathrm{CO}_{2}$ to this peak would be small, because SM showed a smaller peak than SM-Na catalysts despite the former catalyst had a larger surface area than the latter ones (except for SM-Na-1), as listed in Table 1. So, the peaks around $100{ }^{\circ} \mathrm{C}$ was assigned to the desorption of $\mathrm{CO}_{2}$ adsorbed on weak base sites.

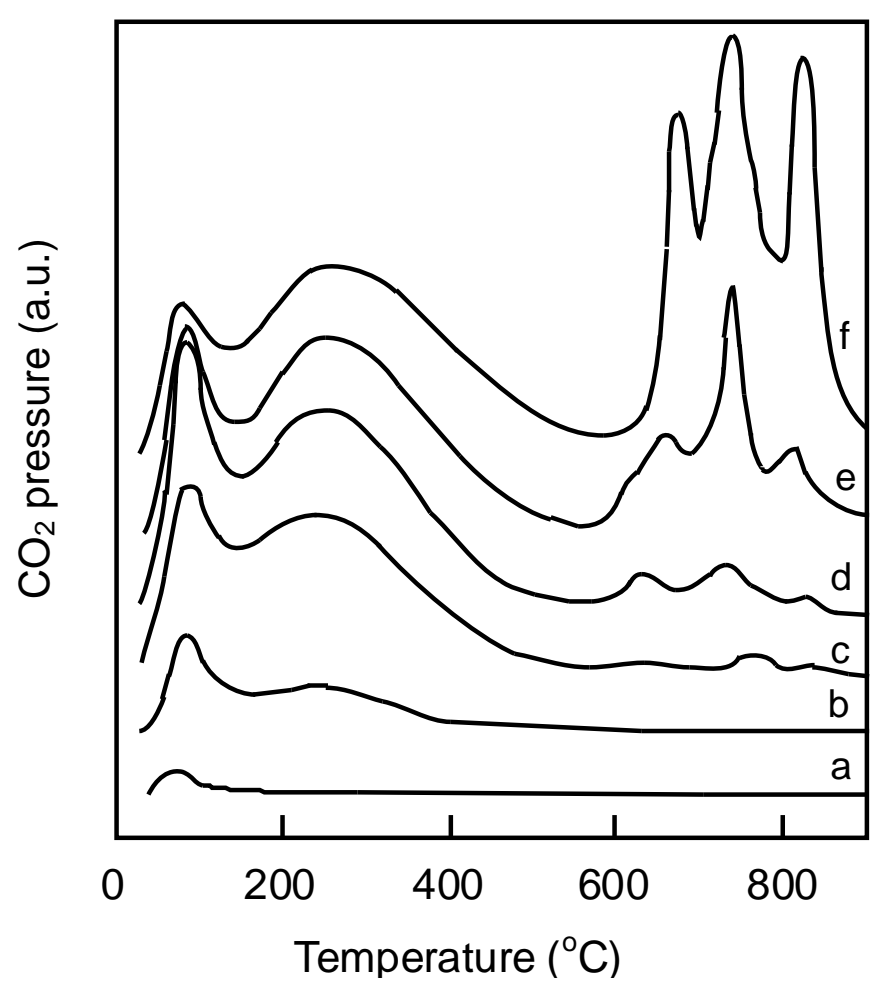

Fig. $2 \mathrm{CO}_{2}$ TPD profiles over smectite samples synthesized. The letters given denote the same samples as given in Tables 1 . 
Although conclusive definition was difficult, the peaks seen between 200 and $600{ }^{\circ} \mathrm{C}$ were tentatively assigned to the desorption of $\mathrm{CO}_{2}$ adsorbed on moderate base sites, while the peaks above $600{ }^{\circ} \mathrm{C}$ to that of $\mathrm{CO}_{2}$ adsorbed on strong base sites. Table 2 lists the amounts of these three-type base sites estimated from the peak areas in the TPD runs. Those structures will be discussed later.

Table 2 Amounts of base sites over smectite catalysts.

\begin{tabular}{lcccc}
\hline \multirow{2}{*}{ Catalyst } & $\begin{array}{c}\text { Number of alkali atoms } \\
\text { per unit cell }\end{array}$ & \multicolumn{3}{c}{ Amount of base site $(\mu \mathrm{mol} / \mathrm{g})$} \\
\cline { 2 - 5 } & 0.09 & 3.1 & Medium & Strong \\
\hline a SM & 0.84 & 18.0 & 37 & 0 \\
b SM-Na-1 & 1.51 & 41.0 & 123 & 9 \\
c SM-Na-2 & 1.80 & 50.7 & 157 & 17 \\
d SM-Na-3 & 2.25 & 44.0 & 165 & 36 \\
e SM-Na-4 & 2.64 & 34.8 & 199 & 100 \\
f SM-Na-5 & $2.17^{\mathrm{a}}$ & 59.5 & 178 & 223 \\
g SM-K & $3.03^{\mathrm{b}}$ & 25.6 & 149 & 78 \\
h SM-Li & & & 109
\end{tabular}

${ }^{\mathrm{a}}$ Sum of $\mathrm{Na}$ and K. ${ }^{\mathrm{b}}$ Sum of $\mathrm{Na}$ and $\mathrm{Li}$.
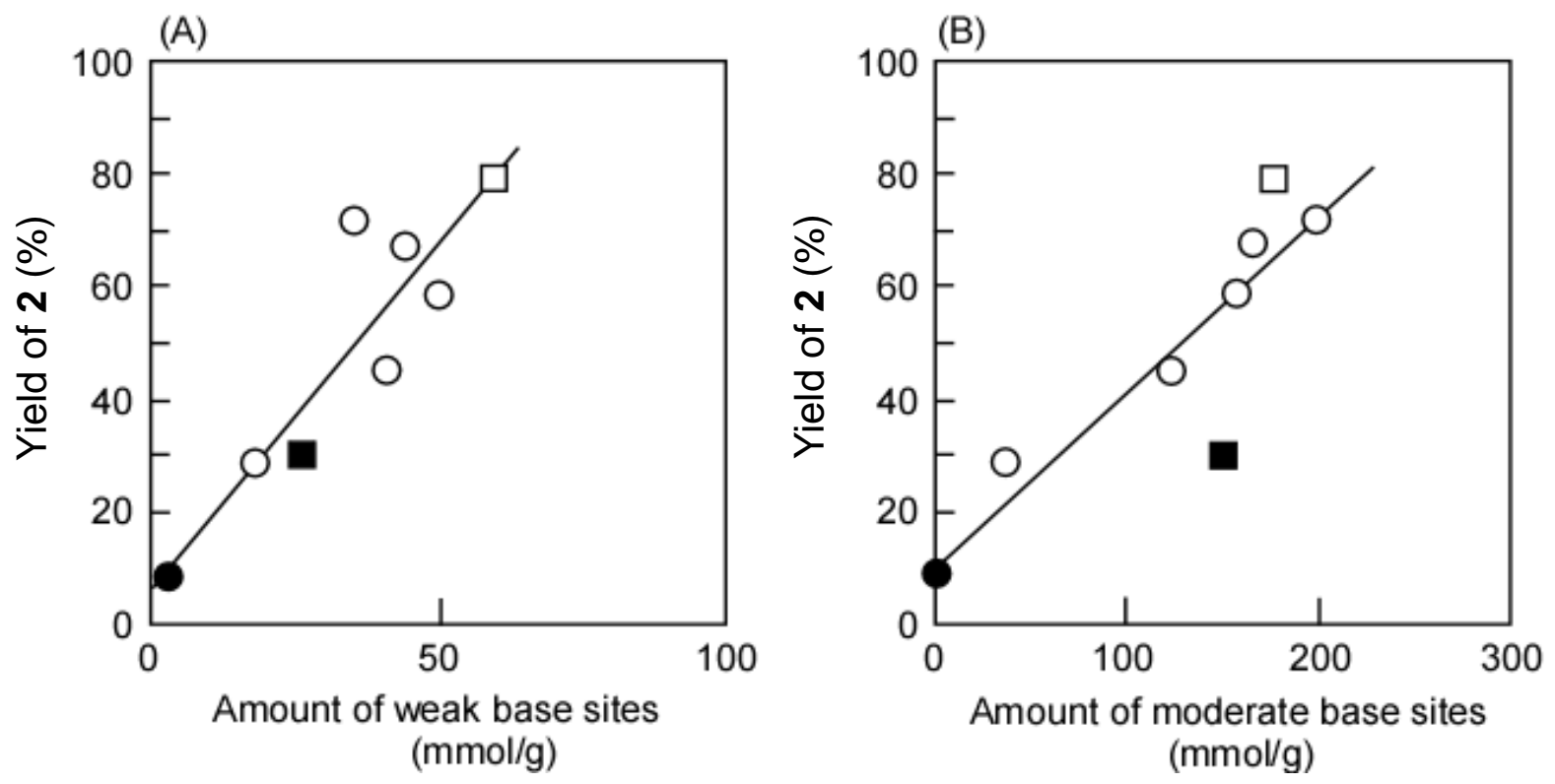

Fig. 3 Relationship between the activity for the synthesis of $\mathbf{2}$ and the amount of (A) weak and (B) moderate base sites of the smectite catalysts. ( ) ), SM; ( ○), SM-Na; ( $\square$ ), SM-K; (匹), SM-Li. 
As shown above, the catalytic activity and the numbers of base sites of smectite increased with the content of alkali atoms. So, the relationship between the catalytic activity observed and the number of basic sites estimated from the peak area in the TPD runs was examined. The activity was correlated well with the amount of either weak or moderate base sites, as shown in Fig. 3. No good correlation was seen with the amounts of strong base sites. These findings strongly suggest that the weak and/or moderate base sites present on the smectite catalysts are responsible for the reaction and the presence of the strong base sites is not required for the reaction.

\section{Influence of reaction conditions and catalyst recycling}

The SM-Na-4 catalyst was selected and used for several reaction experiments by varying the reaction time or the $\mathrm{CO}_{2}$ pressure. Fig. 4 illustrates the variation of the yield of $\mathbf{2}$ with the reaction time. It is seen that an excellent yield above $80 \%$ was achieved within $9 \mathrm{~h}$ but the yield increased marginally in a further longer reaction time of $16 \mathrm{~h}$.

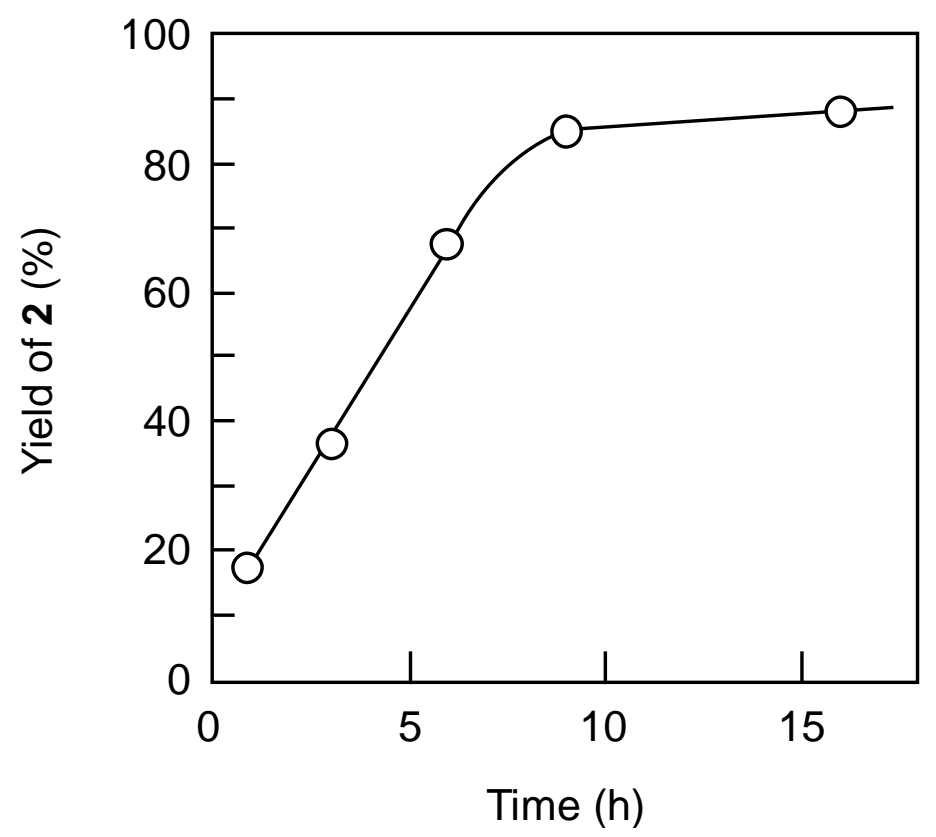

Fig. 4 Influence of reaction time on the synthesis of 2 using SM-Na-4. Reaction conditions: catalyst, $0.4 \mathrm{~g} ; 1,8.5 \mathrm{mmol}$; DMF, $10 \mathrm{~cm}^{3} ; 130^{\circ} \mathrm{C}$.

The influence of $\mathrm{CO}_{2}$ pressure on the reaction was studied (Fig. 5). It was found that the $\mathrm{CO}_{2}$ pressure had little effect on the product yield in a $\mathrm{CO}_{2}$ pressure range between 1 and $4 \mathrm{MPa}$. Even at a lower pressure of $0.5 \mathrm{MPa}$, the decline in the yield was small. These results 
are similar to those obtained with DBU and $\mathrm{Cs}_{2} \mathrm{CO}_{3},{ }^{11,15}$ but different from those obtained with $[\mathrm{Bmim}] \mathrm{OH}$ and $\mathrm{MgO} / \mathrm{ZrO}_{2} \cdot{ }^{16,18}$ With the former two catalysts, the product yield did not change so much at $\mathrm{CO}_{2}$ pressures above $1 \mathrm{MPa}$. With the latter two catalysts, the product yield significantly decreased with lowering the $\mathrm{CO}_{2}$ pressure below $3 \mathrm{MPa}$. Thus, the dependence of the overall reaction rate on the $\mathrm{CO}_{2}$ pressure is different depending on the catalysts employed.

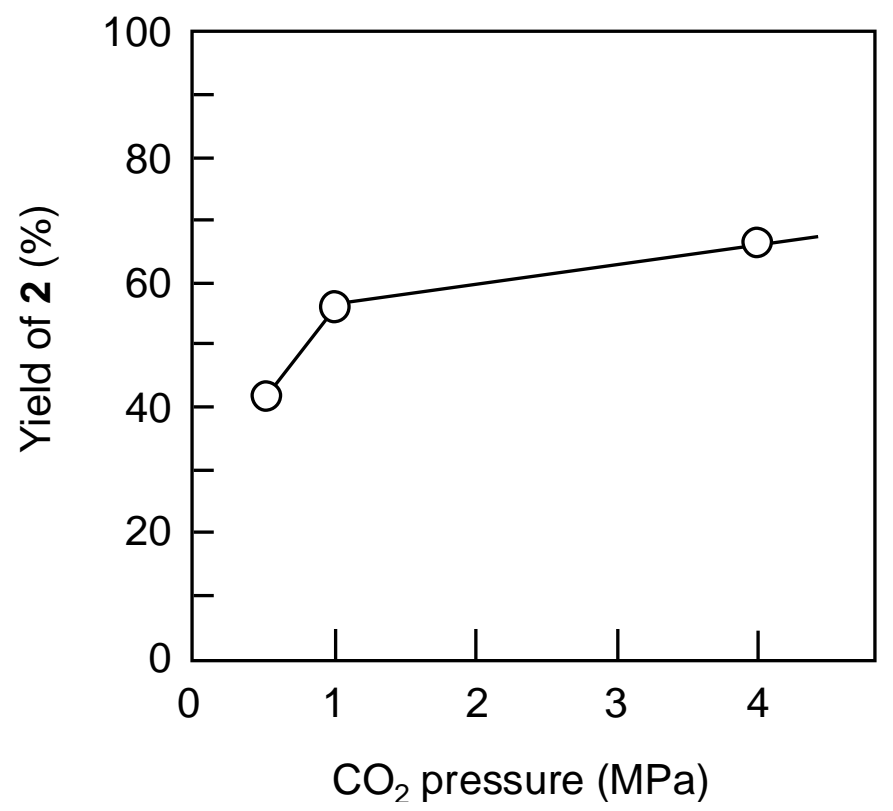

Fig. 5 Influence of $\mathrm{CO}_{2}$ pressure on the synthesis of 2 using SM-Na-4. Reaction conditions: catalyst, $0.4 \mathrm{~g} ; \mathbf{1}, 8.5 \mathrm{mmol}$; DMF, $10 \mathrm{~cm}^{3} ; 130^{\circ} \mathrm{C}$; time, $6 \mathrm{~h}$.

Easy separation and recycling is one of merits of heterogeneous catalysts. So, the recycling tests were conducted with SM and SM-Na-4 to study the stability of the catalysts. In each recycling, the catalyst was separated by filtration after a reaction run, washed with ethanol, dried in air, and then used for the next run. The catalyst activity was evaluated on the basis of the produced amount of $\mathbf{2}$ per weight of the catalyst, because a certain portion of the catalyst was lost during the recycling procedures. The results of recyclability study are illustrated in Fig. 6. SM catalyst could be recycled three times without loss in the activity. On the other hand, the activity of SM-Na-4 changed during the catalyst recycling experiment. It slightly increased after the first recycling and then gradually decreased by repeating the catalyst recycling. To elucidate the reason for the deactivation, the number of $\mathrm{Na}$ atoms in SM-Na-4 recycled five times was measured by XRF. It was found that the number of $\mathrm{Na}$ atoms contained in the recycled catalyst was reduced to below one third of that in the fresh 
one. Furthermore, the textural properties of the catalyst did not change so much by the recycling. These results suggest that the leaching of $\mathrm{Na}$ species occurred in the course of the reaction, causing the deactivation. The reaction runs were also carried out using SM-Na-4 samples pretreated at $130{ }^{\circ} \mathrm{C}$ for $16 \mathrm{~h}$ (corresponding to five-time recycling) in pure DMF under pressurized $\mathrm{CO}_{2}$ or in a DMF solution of 1 in the absence of $\mathrm{CO}_{2}$. It was found that no deactivation occurred by these pretreatments, revealing the requirement of the co-presence of the reactants $\mathbf{1}$ and $\mathrm{CO}_{2}$ for the catalyst deactivation.

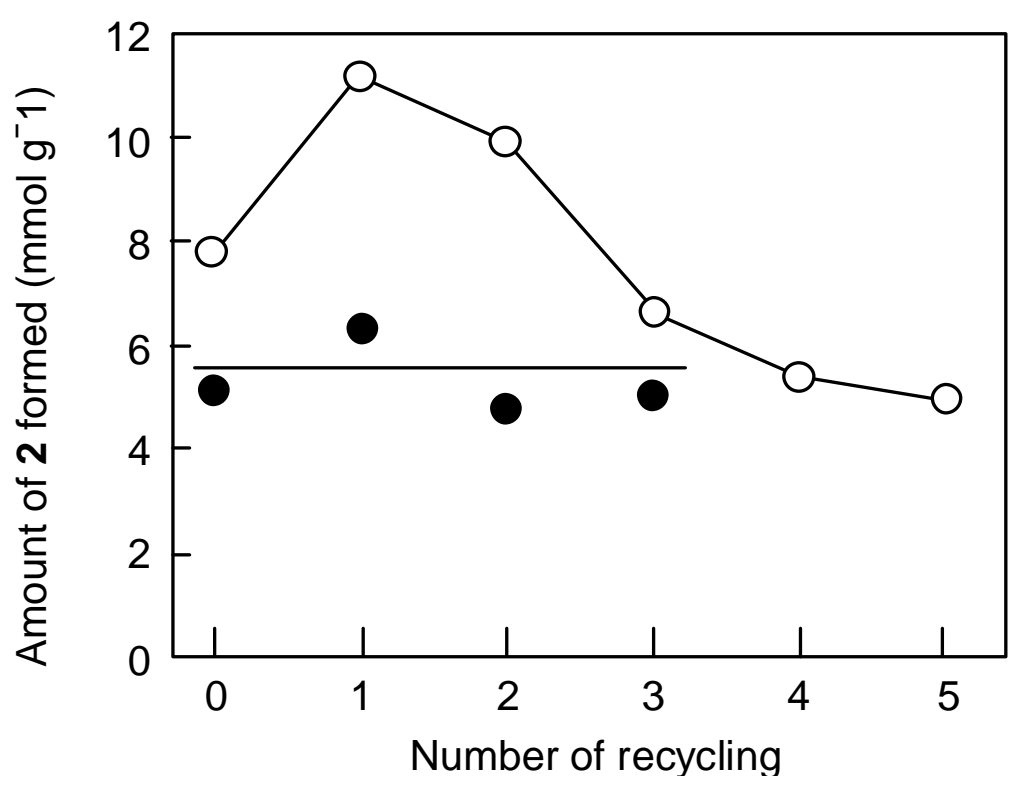

Fig. 6 Recyclability study of ( $)$ SM and ( $\bigcirc$ ) SM-Na-4 on the synthesis of 2. Reaction time was $16 \mathrm{~h}$ and $3 \mathrm{~h}$ for SM and for SM-Na-4, respectively. The other reaction conditions were the same as those for Fig. 1.

The catalytic activity of the leached Na species was examined. After the reaction was carried out with SM-Na-4 for $3 \mathrm{~h}$, it was filtered out from the reaction mixture. Then, the filtrate was further subjected to the reaction for a long time of $19 \mathrm{~h}$. The yield of 2 produced was estimated to be $40 \%$, revealing that the activity of the leached $\mathrm{Na}$ was about one fifth of SM-Na-4, which could produce 2 with a yield about $30 \%$ during the reaction for $3 \mathrm{~h}$. 


\section{Discussion}

As shown in Table 2, the incorporation of alikali atoms to SM significantly increased the amounts of base sites. Among SM-Na samples, the amount of weak base sites showed a maximum at a Na content of 1.8 atoms per a unit cell, but the difference due to the Na content was small. On the other hand, the amounts of moderately and strongly basic sites varied in wider ranges with the $\mathrm{Na}$ content than the weak base sites. The amount of moderately basic sites leveled off at a certain $\mathrm{Na}$ content around 1.8 atoms per a unit cell, and from this content level, the amount of strongly basic site started to increase appreciably. In our previous work, ${ }^{29}$ the features of base sites were discussed and the weak, moderate, and strong base sites were assigned to the surfaces of the smectite layers free from alkali atoms, alkali hydroxide particles having weak or no interactions with the layers, and the ones strongly interacting with the layers, respectively. However, comparison of SM and SM-Na-1 in Table 2 clearly showed that the amount of weak base sites was also significantly increased even with a small amount of $\mathrm{Na}$ incorporation. If the weak base sites are free from $\mathrm{Na}$ atoms, such a change could not be observed. So, the assignments for the weak and moderate base sites were reconsidered and modified. Here, the weak base sites were assigned to both the surfaces of the smectite layers free from alkali atoms and alkali hydroxide particles not interacting at all with the smectite layers, while the moderate ones were assigned to the particles weakly interacting with them. Tanking into account the difference in the amount of the weak base sites between SM and SM-Na-1, the contribution of the alkali free surfaces of the layers to this type of base sites would be small over SM-Na-1. As shown in Fig. 3, the yield of 2 was well correlated to both the amounts of the weak and moderate base sites. It can be said that alkali hydroxide particles have a crucial roll for the synthesis of 2 .

Our group has reported that, over alkali-incorporated smectite catalysts, moderate base sites are responsible for the transesterification reactions of ethyl acetate and propylene carbonate with methanol, while both moderate and strong base sites are responsible for the cycloaddition of $\mathrm{CO}_{2}$ to propylene oxide and the one-pot synthesis of dimethyl carbonate from $\mathrm{CO}_{2}$, methanol and propylene oxide. ${ }^{31,32,34}$ Thus, the types of base sites contributing to the title reaction are different from the ones to those reactions previously studied.

Scheme 2 illustrates the reaction mechanism for the title reaction previously proposed for several different base catalysts. ${ }^{11-17}$ The base catalysts promote the reaction between the amino group of $\mathbf{1}$ and $\mathrm{CO}_{2}$ to produce a carbamate species, which is finally converted to the product 2 through the nucleophilic cyclization and the rearrangement by way of the 
isocyanate intermediate. Usually, the reaction of $\mathrm{CO}_{2}$ with the amino group directly attached to a phenyl ring, for example the amino group of aniline, is more difficult than the one attached to an alkyl chain. The promotional effect of the base on this difficult reaction step would in turn result in the strong interaction between the base and the resultant carbamate species. In the cases of alkali incorporated smestites, alkali hydroxide particles would interact strongly with the intermediate carbamate. As described above, SM-Na-4 was deactivated with decrease of the $\mathrm{Na}$ content in the catalyst on the repeated catalyst recycling and the deactivation was not observed with the pretreatments in the absence of either the reactant $\mathbf{1}$ or the other reactant of $\mathrm{CO}_{2}$. The strong interaction of the alkali particles with the carbamate would cause the dissolution of the alkali species into the solvent, resulting in the catalyst deactivation. It should be noted that the alkali incorporated smectite could be recycled without loss in the activity for the transesterification of ethylene carbonate with methanol. ${ }^{28}$ Thus, the recyclability of the alkali incorporated smectite depends on the reaction for which it is employed.

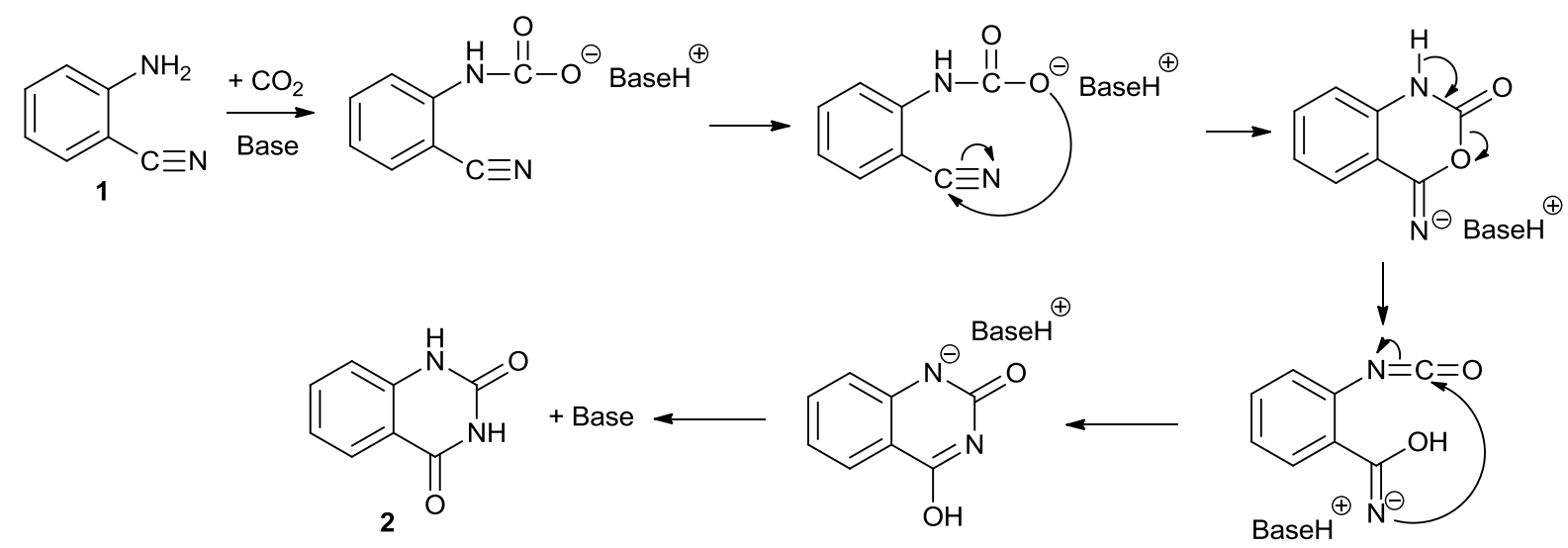

Scheme 2 A reaction mechanism proposed so far for the quinazoline-2,4(1H,3H)-dione synthesis from $\mathrm{CO}_{2}$ and benzonitrile. ${ }^{11-16}$

The catalyst deactivation by the recycling use was not observed with SM (Fig. 5), which contains exchangeable $\mathrm{Na}$ cations compensating the electric charge of the smectite layers but not alkali hydroxide particles. Because $\mathrm{MgO}$ could catalyze the title reaction, ${ }^{18}$ the active sites of $\mathrm{SM}$ would be $\mathrm{Mg}$ atoms and/or the neighboring $\mathrm{O}$ atoms on the surfaces of the smectite layers. The exchangeable Na cations involved in SM might have no or very low activity.

On the basis of the aforementioned discussion, the active sites over SM-Na for the title 
reaction can be illustrated as Fig. 7. There are two types of the active sites. The first and second sites involve $\mathrm{Mg}$ atoms in the octahedral sheet and $\mathrm{NaOH}$ particles existing on the surface of the tri-layer, respectively. A certain fraction of the $\mathrm{NaOH}$ particles weakly interact with the layer. The activity of SM-Na almost depends on the number of the second sites. Naturally, the active sites of SM are the first type.

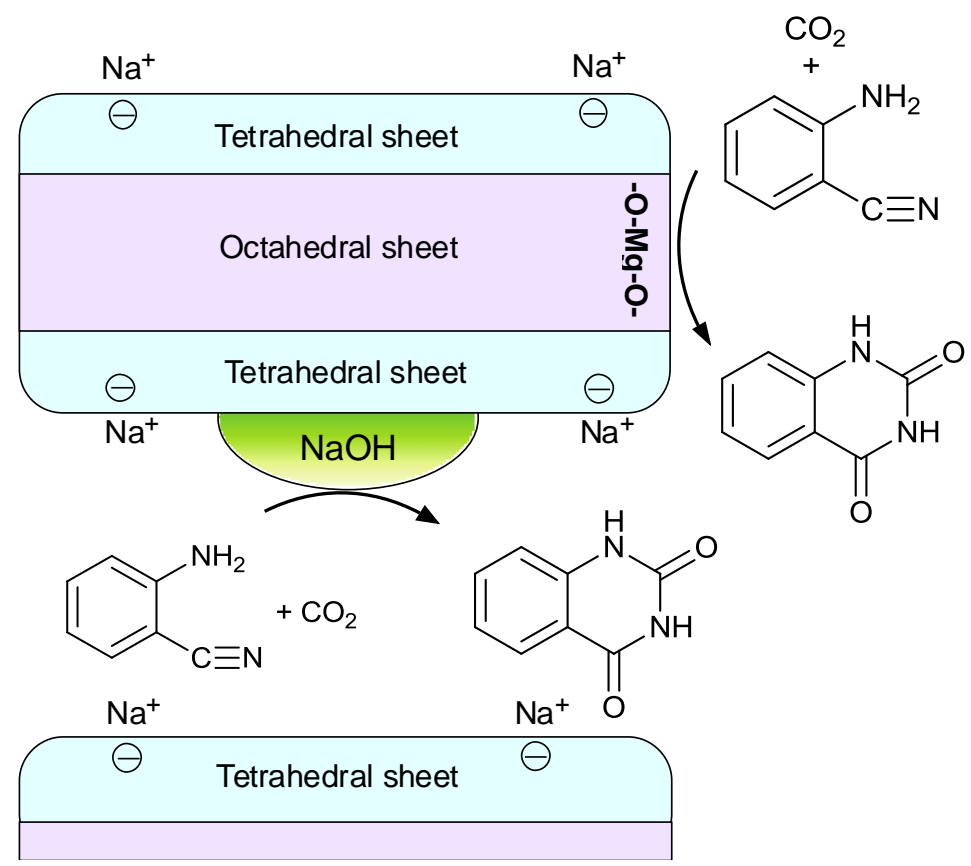

Fig. 7 Active sites over SM-Na catalysts.

Table 3 compares the present catalyst of SM-Na-4 with those in the literature for the synthesis of 2 from 1 and $\mathrm{CO}_{2}$. The organic bases, $\mathrm{Cs}_{2} \mathrm{CO}_{3}$, and [Bmim]Ac could be used at lower temperatures and/or lower $\mathrm{CO}_{2}$ pressures (entries 1-5 and 7). One of the reasons for this would be the homogeneous nature of them. $\mathrm{TBA}_{2}\left[\mathrm{WO}_{4}\right]$ was also more active than SM-Na-4 (Entry 9). Considering the differences in the reaction conditions, the activity of SM-Na-4 is comparable with $[\mathrm{Bmim}] \mathrm{OH}$ and $\mathrm{MgO} / \mathrm{ZrO}_{2}$ (entries 6 and 8). It should again be noted that $[\mathrm{Bmim}] \mathrm{OH}$ and $\mathrm{MgO} / \mathrm{ZrO}_{2}$ gave lower yields of 2 at lower $\mathrm{CO}_{2}$ pressures, while such a decrease in the yield by lowering $\mathrm{CO}_{2}$ pressure was small for the reaction with our SM-Na-4 catalyst (Fig. 5). 
Table 3 Comparison of the present catalyst of SM-Na-4 with the earlier reported ones for the synthesis of $\mathbf{2}$ from $\mathbf{1}$ and $\mathrm{CO}_{2}$.

\begin{tabular}{llccccc}
\hline Entry & Catalyst & 1/Catalyst & $\begin{array}{c}\text { Pressure } \\
(\mathrm{MPa})\end{array}$ & $\begin{array}{c}\text { Temperature/time } \\
\left({ }^{\circ} \mathrm{C} / \mathrm{h}\right)\end{array}$ & $\begin{array}{c}\text { Yield } \\
(\%)\end{array}$ & Reference \\
\hline 1 & DBU & $10 \mathrm{mmol} / 1 \mathrm{mmol}$ & 10 & $80 / 4$ & 91 & {$[12]$} \\
2 & $\mathrm{MTHP}$ & $10 \mathrm{mmol} / 3 \mathrm{mmol}$ & 0.1 & $100 / 24$ & 71 & {$[13]$} \\
3 & Poly-amidine & $0.33 \mathrm{mmol} / 0.33 \mathrm{mmol}$ & 0.1 & $100 / 24$ & 61 & {$[13]$} \\
4 & $\mathrm{TMG}$ & $5 \mathrm{mmol} / 0.1 \mathrm{mmol}$ & 10 & $120 / 4$ & 82 & {$[14]$} \\
5 & $\mathrm{Cs}_{2} \mathrm{CO}_{3}$ & $20 \mathrm{mmol} / 5 \mathrm{mmol}$ & $1.3^{\mathrm{b}}$ & $100 / 4$ & 94 & {$[15]$} \\
6 & {$[\mathrm{Bmim}] \mathrm{OH}$} & $20 \mathrm{mmol} / 5 \mathrm{mmol}$ & $3^{\mathrm{b}}$ & $120 / 18$ & 90 & {$[16]$} \\
7 & {$[\mathrm{Bmim}] \mathrm{Ac}$} & $5 \mathrm{mmol} / 5 \mathrm{mmol}$ & 0.1 & $90 / 10$ & 92 & {$[17]$} \\
8 & ${\mathrm{MgO} / \mathrm{ZrO}_{2}}_{9}$ & $20 \mathrm{mmol} / 0.24 \mathrm{~g}$ & $3.7^{\mathrm{b}}$ & $130 / 12$ & 92 & {$[18]$} \\
9 & $\mathrm{TBA}_{2}\left[\mathrm{WO}_{4}\right]$ & $1 \mathrm{mmol} / 0.02 \mathrm{mmol}$ & 2 & $100 / 24$ & 90 & {$[19]$} \\
10 & $\mathrm{SM}^{\mathrm{N}} \mathrm{Na}-4$ & $8.5 \mathrm{mmol} / 0.4 \mathrm{~g}$ & $4^{\mathrm{b}}$ & $130 / 6$ & 67 & Present study \\
\hline
\end{tabular}

${ }^{\mathrm{a}}$ Tetramethylguanidine.

${ }^{\mathrm{b}}$ Initial pressure at room temperature.

${ }^{\mathrm{c}}$ Water is mandatory as the solvent.

As shown above, the incorporation of alkali hydroxide into smectite greatly enhanced the catalytic activity for the title reaction. This was attributed to the formation of alkali hydroxide particles between the smectite layers. Unfortunately, the catalytic activity was decreased by the repeated use because of the dissolution of the active alkali species into the solvent. The stability of the catalyst may further be improved by optimizing preparation conditions and incorporation of different metal cations into the octahedral sheet and/or the interlayer. Those aspects are open for further interesting work. A few groups employed supercritical $\mathrm{CO}_{2}$, water, or an ionic liquid as a green solvent for the title reaction. ${ }^{11,16,17,20}$ The use of the smectite catalysts in those media is also interesting and worth investigating in future.

\section{Conclusions}

In the present study, a series of magnesium containing mesoporous smectites (SM, M-Na, SM-K, SM-Li) has been prepared with and without incorporation of alkali hydroxide and employed for the synthesis of $\mathbf{2}$. The incorporation of alkali atoms reduces their surface area 
and total pore volume but enhances the amount and strength of their basic sites. The product yield is increased with the content of alkali atoms incorporated. The incorporation of Li is less effective than $\mathrm{Na}$ and $\mathrm{K}$ for the enhancement of the yield. It has been suggested that weak and/or moderate base sites involving alkali hydroxide particles existing between the smectite layers are responsible for the reaction. The $\mathrm{Na}$ incorporated smectite is deactivated by the repeated catalyst recycling because of the dissolution of the Na species into DMF. Such a deactivation is not observed with SM. It has been proposed that there is strong interaction between $\mathrm{NaOH}$ particles and the reaction intermediate species of carbamate, resulting in the catalyst deactivation.

\section{Experimental}

\section{Synthesis of smectite catalysts}

A smectite catalyst was synthesized with a hydrothermal method in which water glass $\left(\mathrm{SiO}_{2}\right.$ $\left.28 \%, \mathrm{Na}_{2} \mathrm{O} 9 \%\right)$ was used as the starting material. Water glass $(12.9 \mathrm{~g})$ was dissolved in 30 $\mathrm{cm}^{3}$ of water. To this solution, $22.5 \mathrm{~cm}^{3}$ of a $2 \mathrm{~N} \mathrm{NaOH}$ solution and $30 \mathrm{~cm}^{3}$ of a solution containing magnesium chloride hydrate were consecutively added under stirring. The resulting solution was kept under stirring at ambient temperature for $15 \mathrm{~h}$. Si-Mg precipitates that formed was separated by filtration and washed with water 4 times. A slurry was prepared from the Si-Mg precipitates and $20 \mathrm{~cm}^{3}$ of water. Then the slurry was transferred into an autoclave and heated at $200{ }^{\circ} \mathrm{C}$ under autogaseous water vapor for $3 \mathrm{~h}$. The product obtained was filtered and dried at $100{ }^{\circ} \mathrm{C}$ for $15 \mathrm{~h}$. This catalyst is designated as SM herein.

Several smectites incorporated with alkali hydroxides were also prepared in a similar manner in which some amount of sodium, potassium or lithium hydroxide was added to the slurry of Si-Mg precipitates before the hydrothermal treatment. The procedures for these alkali incorporated smectites were described in elsewhere. ${ }^{27}$ These catalysts are abbreviated as SM-Na-n ( $=1-5)$, SM-K, and SM-Li. The chemical compositions of the smectite catalysts prepared were determined by an X-ray fluorescence method and listed in Table 1.

\section{Characterization of catalysts}

X-ray powder diffraction (XRD) patterns of the smectite samples prepared were recorded on a JEOL JDX-8030 diffractometer using Ni filtered $\mathrm{Cu}-\mathrm{K} \alpha$ radiation. The samples were scanned 
in the range of $2-70^{\circ}$ with a step of $0.02^{\circ}$. BET surface area, total pore volume, and pore size distribution were obtained from nitrogen adsorption-desorption isotherms at $-196{ }^{\circ} \mathrm{C}$ with a Nova 1200 automatic physisorption instrument (Quantachrome Corporation). The samples were degassed at $100^{\circ} \mathrm{C}$ under vacuum for $30 \mathrm{~min}$ prior to the measurements.

Basic properties of the catalysts were measured by temperature programmed desorption (TPD) of adsorbed $\mathrm{CO}_{2}$ using a conventional flow reactor. After a stream of 20 vol.\% $\mathrm{CO}_{2}-\mathrm{He}$ mixture was passed over $0.2 \mathrm{~g}$ of a catalyst sample at room temperature for $20 \mathrm{~min}$, gases in the reactor were flushed with a helium stream. Then the temperature was ramped at a heating rate of $10 \mathrm{~K} / \mathrm{min}$ up to $900{ }^{\circ} \mathrm{C}$. The effluent from the reactor was analyzed by mass spectrometry.

\section{Catalytic reaction}

The synthesis of 2 was carried out in a $50 \mathrm{~cm}^{3}$ autoclave. In a typical run, the reactor was charged with the catalyst $(0.4 \mathrm{~g}), \mathbf{1}(8.5 \mathrm{mmol})$ and DMF $\left(10 \mathrm{~cm}^{3}\right)$ and purged with $\mathrm{CO}_{2}$ several times, and then liquid $\mathrm{CO}_{2}$ was further injected into the reactor up to $4 \mathrm{MPa}$ under stirring. The reaction mixture was stirred at $130^{\circ} \mathrm{C}$ for $6 \mathrm{~h}$. After the reaction, the catalyst was filtered off, washed with ethanol, and dried under vacuum. The filtrate was evaporated in vacuum to remove the solvent of DMF and the un-reacted 1 . The crude product of 2 was washed with diethyl ether and dried under vacuum.

\section{References}

1. M. Aresta and A. Dibenedetto, Catal. Today, 2004, 98, 455-462.

2. T. Sakakura, J.C. Choi and H. Yasuda, Chem. Rev., 2007, 107, 2365-2387.

3. T. Sakakura and K. Kohno, Chem. Commun., 2009, 1312-1330.

4. G. Pastor, C. Blanshard, C. Montginoul, E. Torreilles, L. Giral and A. Texier, Bull. Soc. Chim. Fr., 1975, 1331-1338.

5. M. Kahalifa, A.N. Osman, M.G. Ibrahim, A.R.E. Ossman and M.A. Ismail, Pharmazie., 1982, 37, 115-117.

6. M. Michman, S. Patai and Y. Wiesel, Org. Prep. Proced. Int., 1978, 10, 13.

7. N.A. Lange and F.E. Sheibley, Org. Synth. Coll. Vol. II, Wiley, London, 1943, p 79.

8. H. Vorbrueggen and K. Krolikiewicz, Tetrahedron, 1994, 50, 6549-6558. 
9. T. Mizuno, N. Okamoto, T. Ito and T. Miyata, Tetrahedron Lett., 2000, 41, 1051-1053.

10. T. Mizuno and Y. Ishino, Tetrahedron, 2002, 58, 3155-3158.

11. T. Mizuno, T. Iwai and Y. Ishino, Tetrahedron Lett., 2004, 45, 7073-7075.

12. T. Mizuno, M. Mihara, T. Nakai, T. Iwai and T. Ito, Synthesis, 2007, 2524-2528.

13. D. Nagai, T. Endo, J. Polym. Sci. Part A, 2009, 47, 653-657.

14. J. Gao, L.N. He, C.X. Miao, S. Chanfreau, Tetrahedron, 2010, 66, 4063-4067.

15. Y. P. Patil, P.J. Tambade, S.R. Jagtap and B.M. Bhanage, Green. Chem.. Lett. Rev., 2008, 1, 127-132.

16. Y. P. Patil, P.J. Tambade, K. M. Deshmukh and B.M. Bhanage, Catal. Today, 2009, 148, $355-360$.

17. W. Lu, J. Ma, J. Song, Z. Zhao, G. Yang, B. Han, Green Chmeistry, 2014, 16, 221-225.

18. Y. P. Patil, P.J. Tambade, K. D. Parghi, V. Jayaram and B.M. Bhanage, Catal. Lett., 2009, 133, 201-208.

19. T. Kimura, K. Kamato, N. Mizuno, Angew. Chem. Int. Ed., 2012, 51, 6700-6703.

20. J. Ma, B. Han, J. Song, J. Hu, W. Lu, D. Yang, Z. Zhang, T. Jiang, M. Hou, Green Chmeistry, 2013, 15, 1485-1489.

21. K. Torii, T. Iwasaki, Y. Onodera and M. Shimada, Nippon Kagaku Kaishi, 1989, 345-351.

22. K. Torii, T. Iwasaki, Y. Onodera and T. Nishiyama, J. Ceram. Soc. Jpn., 1992, 100, $368-372$.

23. K. Torii and T. Iwasaki, Chem. Lett., 1988, 2045-2048.

24. E. Suzuki, S. Idemura and Y. Ono, Appl. Clay. Sci., 1988, 3, 123-134.

25. Y. Nishiyama, M. Arai, S.-L. Guo, N. Sonehara, T. Naito and K. Torii, Appl. Catal. A: Gen., 1993, 95, 171-181.

26. M. Arai, M. Kanno, Y. Nishiyama, K. Torii and M. Shirai, J. Catal., 1999, 182, 507-510.

27. K. Torii, Y. Onodera, T. Iwasaki, M. Shirai, M. Arai and Y. Nishiyama, J. Porous Mater, 1997, 4, 261-268.

28. M. Arai, Y. Minato, K. Torii and M. Shirai, Catal. Lett., 1999, 61, 83-87.

29. M. Shirai, K. Aoki, K. Torii and M. Arai, Appl. Catal. A: Gen., 1999, 187, 141-146.

30. K. Torii and T. Iwasaki, Clay Sci., 1987, 7, 1-16.

31. S. Fujita, B. M. Bhanage, Y. Ikushima, M. Shirai, K. Torii and M. Arai, Catal. Lett., 2002, 79, 95-98.

32. B. M. Bhanage, S. Fujita, Y. He, Y. Ikushima, M. Shirai, K. Torii and M. Arai, Catal. Lett., 2002, 83, 137-141.

33. B. M. Bhanage, S. Fujita, Y. Ikushima, K. Torii and M. Arai, Green Chem., 2003, 5, 
(2003) 71-75.

34. S. Fujita, B.M. Bhanage, D. Aoki, Y. Ochiai, N. Iwasa and M. Arai, Appl. Catal. A: Gen., 2006, 313, 151-159. 
Graphical Abstract

Synthesis of quinazoline-2,4(1H,3H)-dione from carbon dioxide and 2-aminobenzonitrile using mesoporous smectites incorporated with alkali hydroxide

Shin-ichiro Fujita, Masahiro Tanaka and Masahiko Arai

Incorporation alkali hydroxide into smectite significantly enhances the catalytic activity for the synthesis of quinazoline-2,4(1H,3H)-dione from carbon dioxide and 2-aminobenzonitrile, which has been ascribed the formation of $\mathrm{NaOH}$ particles on the surface of the smectite layer.

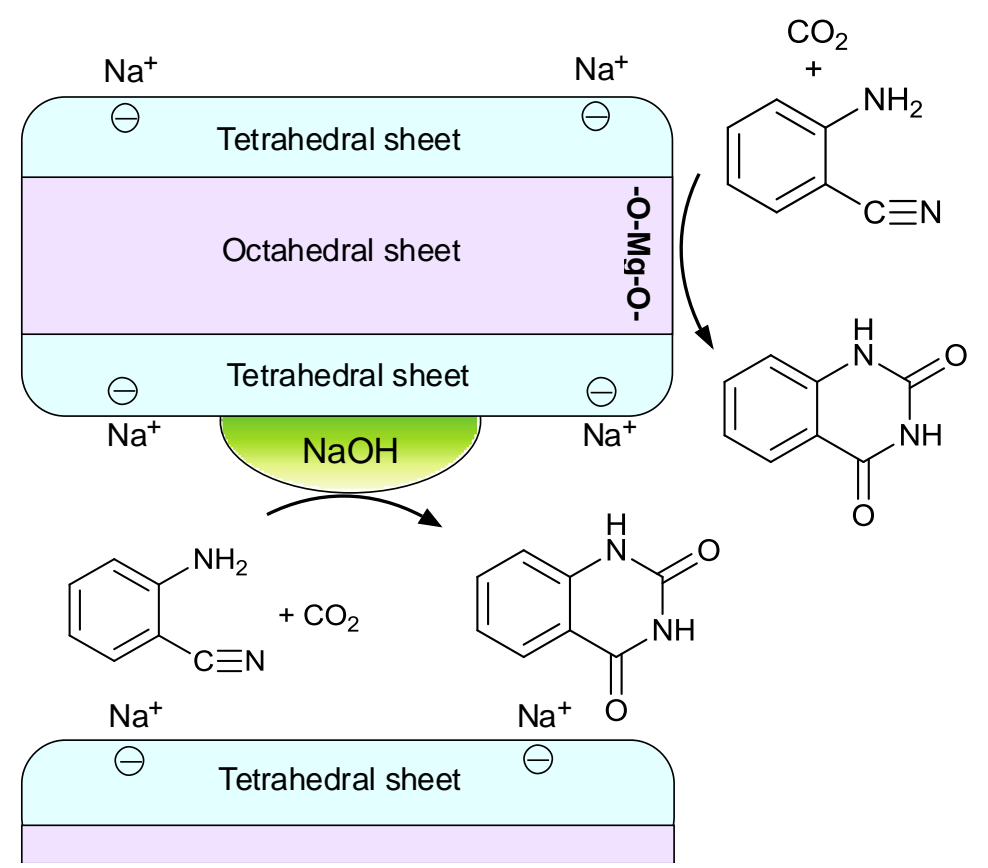

